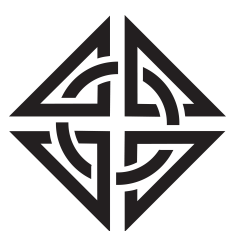

SCIENTIA

I RAN I CA
Sharif University of Technology

Scientia Iranica

Transactions A: Civil Engineering

http://scientiairanica.sharif.edu

\title{
Experimental and numerical assessment of the lateral resistance of ballasted railway track equipped with mid-winged sleeper
}

\author{
B. Sadollahzadeh ${ }^{\mathrm{a}}$, J.A. Zakeri ${ }^{\mathrm{b}, *}$, H. Nouri Gheshlaghic, and A. Hasani Motlagh ${ }^{\mathrm{a}}$ \\ a. Department of Civil Engineering, Sharif University of Technology (SUT), Azadi Avenue, Tehran, Iran. \\ b. Center of the Excellence for Rail Transportation, School of Railway Engineering, Iran University of Science and Technology \\ (IUST), Narmak, Tehran, Iran. \\ c. School of Railway Engineering, Iran University of Science and Technology (IUST), Narmak, Tehran, Iran.
}

Received 26 September 2020; received in revised form 4 January 2021; accepted 19 July 2021
KEYWORDS
Ballasted railway track;
Lateral resistance;
Mid-winged sleeper;
STPT;
LTPT;
Experimental and numerical modelling.

\begin{abstract}
In order to reduce the possibility of buckling problems related to the railway ballasted tracks, necessary measurements should be applied to improve the lateral resistance of tracks. There are different procedures for increasing the lateral force resistance of railway tracks that can be implemented using different materials to change the size, geometry, and dimensions of track components, especially sleepers. Although several studies have been conducted on winged sleepers, the present study investigates the application of mid-winged sleepers with a modified geometry and a dimension in the form of a novel approach. In this regard, several experimental tests and numerical modeling were conducted on the lateral resistance of conventional and mid-winged sleepers. To this end, single sleeper experiment for lateral resistance of the track panel, consisting of five sleepers, was carried out. The lateral force resistance of tracks was measured through the track panel loading and single sleeper push tests. The results revealed that by changing the conventional track to the mid-winged track, the lateral force resistance would considerably increase. The mid-winged panel tests, single mid-winged sleeper tests, and numerical modeling pointed to a $58 \%-64 \%$ increase in the lateral force resistance of mid-wing track, compared to the conventional tracks.

(C) 2021 Sharif University of Technology. All rights reserved.
\end{abstract}

\section{Introduction}

Lateral, longitudinal, and vertical forces are imposed on the rail track and the resistance of forces in each direction should be fully supplied. Vertical forces represent a basis for the design of rail tracks. However, it is necessary to control the stability of tracks in both lateral and longitudinal directions [1]. Faster deterioration of track geometry and greater maintenance costs

*. Corresponding author.

E-mail address: Zakeri@iust.ac.ir (J.A. Zakeri)

doi: $10.24200 /$ sci.2021.56873.4955 may be the result of the increased lateral forces of Continuous Welded Rail (CWR) tracks. The lateral resistance of ballasted tracks is provided by a fastener, rail, and interaction between ballast and sleeper [2]. On the contrary, ballast resistance against the lateral load consists of three parts: friction of the sleeper base, friction of the side of the sleeper, and passive pressure induced at the end of the sleeper [3]. With the consideration of the resistance mechanisms in each of the mentioned parts, the lateral resistance can increase through some alterations [4].

Keeping in mind the critical role of lateral force resistance in railways, numerous researchers have conducted different studies in this field. For instance, Le 
Pen and Powrie [5] evaluated the relative contribution of the base, shoulder ballast, and crib behavior to the lateral force resistance. Throughout their study, they suggested different methods for minimizing the lateral displacement of tracks. Generally, there are three groups of strategies for increasing the lateral force resistance of tracks:

1. Changing the shape, dimensions, and material of track components;

2. Using new technologies in the railway tracks;

3. Changing the maintenance plan and track geometry [6].

The first one improves the lateral force resistance by modifying the interaction between the ballast and sleeper. Changing the shape of the sleeper was also studied which demonstrated $65 \%$ and $30 \%$ increase in the lateral force resistance of the frictional sleeper [7] and twin block sleeper [8], respectively. As the second solution to enhancing the lateral resistance, new technologies in the railway tracks are nowadays implemented to decrease the lateral displacements. Sabaghi [9] conducted a series of single tie push tests and demonstrated that the lateral force resistance increased by $19 \%$ while implementing the sleeper anchors. Utilization of Under Sleeper Pads (USP) [10], polyurethane bonding method [11], baby gabion [12], and geosynthetics [13] represent other pragmatic factors that affect the lateral force resistance. The third solution to modifying the lateral behavior involves the maintenance plan and changing the track geometry. Kabo [14] investigated the lateral force resistance of the ballast with 3D elastoplastic simulations. He found out that the shoulder width could significantly affect the lateral force resistance. Upon increasing the shoulder width, an increase was observed in the volume and weight of the resisting wedge against the lateral displacement of the sleeper [15].

Winged sleeper is an example of the mentioned methods for increasing the lateral behavior of tracks through changing the geometry sleeper and adding some parts to the sides. Winged sleeper is a type of concrete sleeper invented in the 1970 s when the innovation of sleeper shape, especially concrete sleepers with two wings on both ends, was typical. The midwinged sleeper has a middle wing at its center instead of concrete wings on both ends. The most crucial middle wing task in mid-winged sleepers is to apply the optimum ballast capacity in order to prevent displacement and movement in the lateral direction. Upon initiating a pressure-resistant process, the mid-wing of this type of sleeper prevents lateral displacement against the load of the rail tracks using shoulder ballast and ballast of the crib zone. As mentioned earlier in the continuous welded track, the resistance resulting from this process, particularly in the small radius curves, is critical since $65 \%$ of the lateral track resistance is provided by the ballast [1]. Another advantage of using this type of sleeper is its ability to reduce the vertical stress in the ballast. With this type of sleeper and wider subsurface in the loading area, the vertical stress is reduced and a better distribution of stress occurs, thus providing the possibility of increased vertical load that can be taken into account in designing the sleepers to be used in tracks with heavy axial load. The advantages of the mid-winged sleepers and winged sleepers have been already mentioned; however, during the construction/maintenance operations, the winged sleeper may encounter some problems such as handling of maintenance tools and machinery (in particular tamping tines). That is the reason for production of the mid-winged sleepers; in other words, while keeping the advantages of winged sleepers, the possible problems and defects can also be eliminated.

The earliest study in this regard is the research carried out by Austrian Federal Railways called Be14. These sleepers were designed to be fit for mountainous tracks with small radius curves $(R>450)$ and highspeed lines. In these studies, the rate of lateral load resistance of winged sleepers was compared with that of the conventional sleepers, indicating $90 \%$ increase in the resistance of the winged sleepers compared to the conventional ones [16]. A numerical study was carried out on winged sleepers in Spain with emphasis on the significance of welded rails with high curvature and heat exposure on the lateral resistance. A problematic railway line was analyzed in Spain so that a solution could be suggested for the improvement of its condition $[17,18]$. In order to evaluate the resistance of the sleeper inside the ballast, Koike et al. constructed a test section of the track on a scale of one-fifth of the actual track. Hayano et al. conducted a series of track panel pull-out tests and single-sleeper pull-out tests on $1 / 5$ models of the end-winged and parallelepiped sleepers to evaluate the effect of the shape of the sleeper on the lateral resistance of the sleepers in ballasted tracks. Their results revealed that the end-winged sleepers could resist horizontal loads 1.5 times more than rectangular parallelepiped sleepers [19]. Jing et al. (2019) conducted a number of single tie push tests to evaluate the performance of middle-winged, end-winged, and bumped sleepers in ballasted tracks with different shoulder ballast heights and widths. According to their findings, the end-winged sleepers exhibited higher lateral resistance and the optimum shoulder height and width were calculated by $150 \mathrm{~mm}$ and $500 \mathrm{~mm}$, respectively. The higher strength of endwinged sleeper, rather than middle-winged one, can be attributed to the higher contact forces between the shoulder ballast and the ending part of end-winged sleepers. However, there might be some problems 
in end-winged sleeper in terms of track maintenance operation, particularly in the track tamping process, which can be eliminated in mid-winged sleepers [20]. Although the application of winged sleepers generally results in $35 \%$ higher lateral resistance than that in rectangular types, the challenge of the track tamping process and maintenance still exists, which can be mostly eliminated using mid-winged sleepers. Installation of sleeper steel anchors is another method for improving the lateral resistance of the implemented sleepers. Despite winged sleepers, sleeper anchors can be assembled and separated easily and quickly during maintenance operations. However, in the course of implementing anchors on every sleeper instead of the alternate sleeper, there would be relatively slight lateral resistance enhancement [21].

In this study, different types of sleepers including the conventional sleeper with rectangular and trapezoidal sections and winged sleepers with identical sections and wings of 20 and $40 \mathrm{~mm}$ were considered for further use. The test results indicated an increase in the lateral resistance by more than $70 \%$ [22]. Zakeri and Hassanrezaei [6] conducted a series of experimental evaluations of the effect of winged sleepers on the lateral resistance in a ballasted track. According to their findings, the lateral resistance of a winged sleeper exhibited a $101 \%$ increase compared to the conventional sleeper.

The present study investigated the role of midwinged sleepers as a new approach to reducing the lateral displacements of railway tracks and maintenance and operation costs of winged sleepers. The lateral resistance of mid-winged and conventional sleepers was also studied using experimental and numerical investigations.

\section{Design and manufacturing of mid-winged sleeper}

The manufacturing procedure of either conventional winged sleeper or mid-winged sleeper is identical and there is no considerable difference in this regard. The only difference in the manufacturing of this sleeper is the change in the mold concerning this type of sleeper.

The middle wing is trapezoidal in shape with upper and lower sides of about $580 \mathrm{~mm}$ and $610 \mathrm{~mm}$, respectively. The height of the sleeper is equal to that of the central section of the sleeper, which is approximately $175 \mathrm{~mm}$ (Figure 1(a) and (b)).

Given the profile/specifications of the winged and mid-winged sleepers, the amount of the used concrete and increased weight, and the bottom surface of the sleeper, the conditions of both options are almost identical (see Table 1). Therefore, since the test conditions are accepted, the mid-winged sleeper may be substituted and regarded as a better alternative.

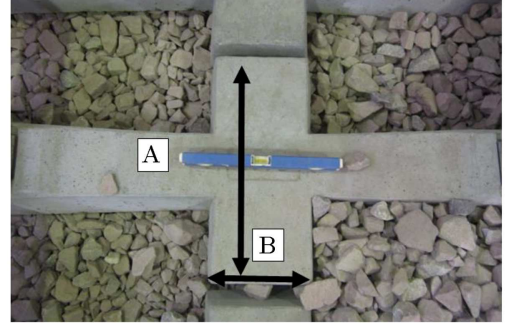

(a)

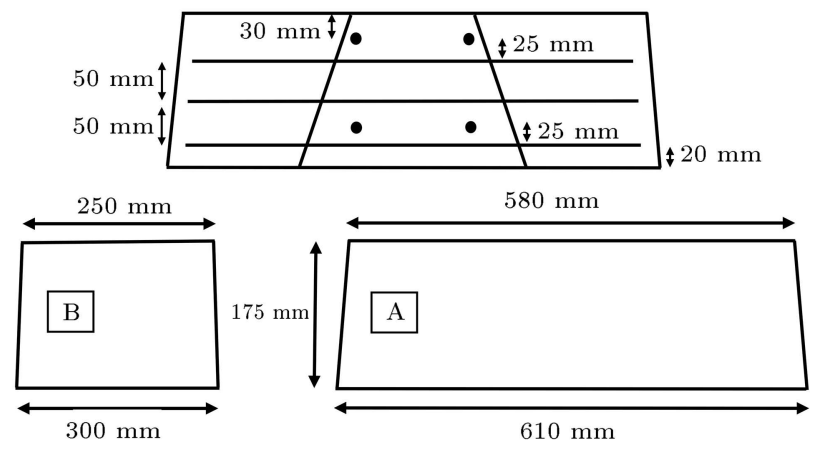

(b)

Figure 1. (a) Scheme of mid-winged sleeper. (b) Mid-winged sleeper dimensions.

Table 1. Mid-winged sleeper profile specifications.

\begin{tabular}{lcc}
\hline \multicolumn{1}{c}{ Feature } & Unit & $\begin{array}{c}\text { Mid } \\
\text {-winged }\end{array}$ \\
\hline Weight & $\mathrm{kg}$ & 325 \\
Length & $\mathrm{mm}$ & 2600 \\
Section width without wing & $\mathrm{mm}$ & 160 \\
Section width with wing & $\mathrm{mm}$ & 580 \\
\hline
\end{tabular}

According to Figure 1(b), in the mid-winged sleeper, reinforcement wires are inserted in the middle wing with a length of $550 \mathrm{~mm}$ in three double rows.

The spacing between the reinforcement rows inside the wing is $50 \mathrm{~mm}$. Moreover, the distance between the reinforcement wires of the main sleeper body and the existing reinforcement wires in the sleeper wing is $25 \mathrm{~mm}$, which in the concrete space is in a state of skew lines relative to each other.

\section{Tests performed to measure lateral resistance}

There are different ways to measure the lateral resistance. This study applied two Single Individual Tie (sleeper) Push Test (STPT) and Lateral Track Panel Loading Test (LTPT) tests which could measure the lateral resistance and increase lateral resistance in a sleeper and consequently in a track panel consisting of 5 sleepers. Other methods such as track mechanical displacement [23] and track dynamic displacement methods $[17,24]$ were employed in this study. 


\subsection{Single Sleeper (tie) Push Test (STPT)}

In this method, the STPT test device with a hydraulic jack and a displacement recording instrument exports the lateral force into a sleeper (fastening of which is unscrewed) and the force changes measured against displacement created in the direction of force are also exported, as presented in Figure 2(b) and (c). For loading, first, the sleeper fastenings are primarily unscrewed; then, the jack of the STPT device is placed on one rail and the displacement recording instrument is placed on another. The loading continues until reaching the displacement of $2 \mathrm{~mm}$, and the results are recorded per $0.5 \mathrm{~mm}$ displacement. The test is repeated three times to check the accuracy of the results and prevent probable errors that may occur during the STPT test. Next, after each test, the track panel area undergoes tamping to restore the ballast conditions to the primary state. Ballast materials are obtained from the crushed stone with aggregation, as shown in Figure 2(a). In this figure, the desired case corresponds to aggregation No. $1[25,26]$. The ballast specification is prepared based on the Technical-General Specifications for Railway Track Superstructure, published by Iran Planning and Strategic Bureau of Presidential Office, Islamic Republic of Iran [25].

The STPT test is also repeated for the mid-winged concrete sleeper three times. The results are presented in Figure 2(d) and (e).

\subsection{Lateral Track Panel Loading Test (LTPT)}

In this experiment, two main parameters of force and displacement are calculated. The lateral force is horizontally imported with $90^{\circ}$ angle towards the track panel alignment. Since the test is static, the force is imported at a steady and uniform rate and low speed (Figure 3(a)). A displacement is also recorded by a gradual increase in force, corresponding to each force $[17,18]$. According to other lateral resistance tests, the criteria for this test are the displacement of the standard $2 \mathrm{~mm}$. It is still possible to continue the testing up to higher displacement rates and the desired force values. We proceed with studying the components, tools, and equipment used in the test as well as the test structure. As the first step, a fixed and firm support should be established. Since the imported force used in this test is more than $20 \mathrm{kN}$, a very firm and rigid support should be used in accordance with the results of previous tests.

The track panel loading test for the conventional sleeper is carried out three times (see Figure 3(b)). The test for the mid-winged concrete sleeper is also conducted three times. The results are presented in Figure 4(a) and (b).

\subsection{Analysis of STPT test results}

In this section, the STPT test results are analyzed for both mid-winged and conventional sleepers. Since the

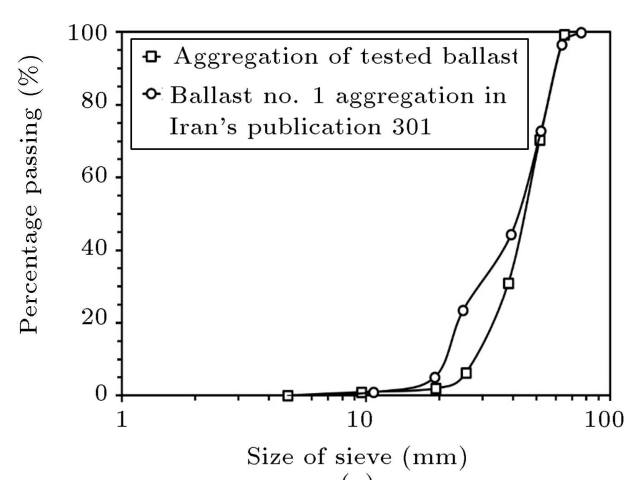

(a)

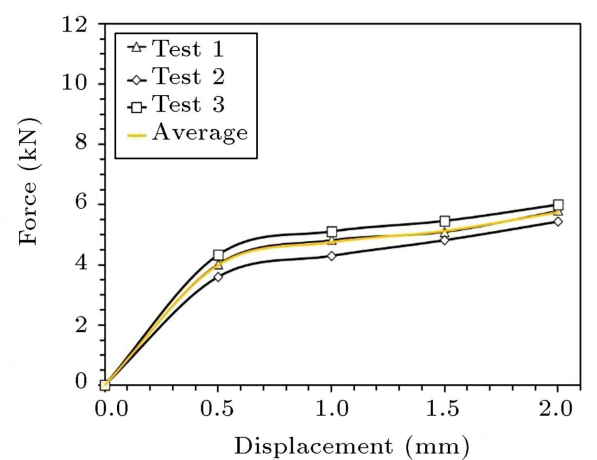

(d)

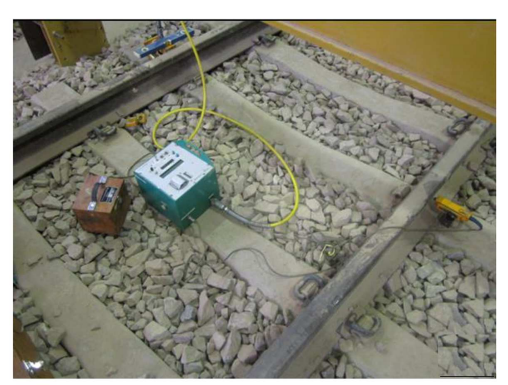

(b)

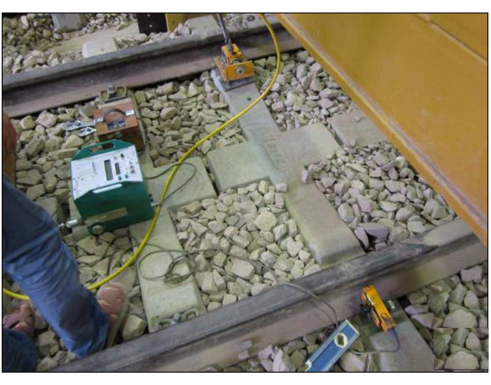

(c)

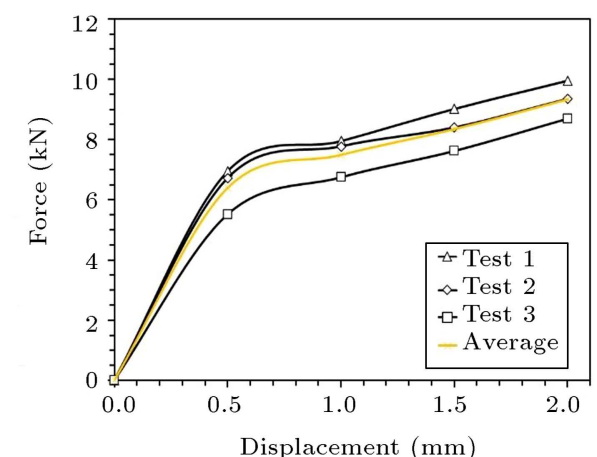

(e)

Figure 2. (a) Sizing of ballast aggregate; Single sleeper push test. (b) Conventional concrete sleeper. (c) Mid-winged concrete sleeper; STPT test results. (d) Conventional concrete sleeper. (e) Mid-winged concrete sleeper. 


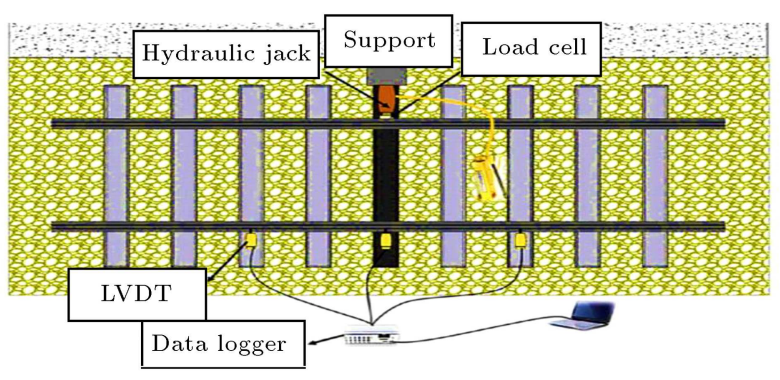

(a)

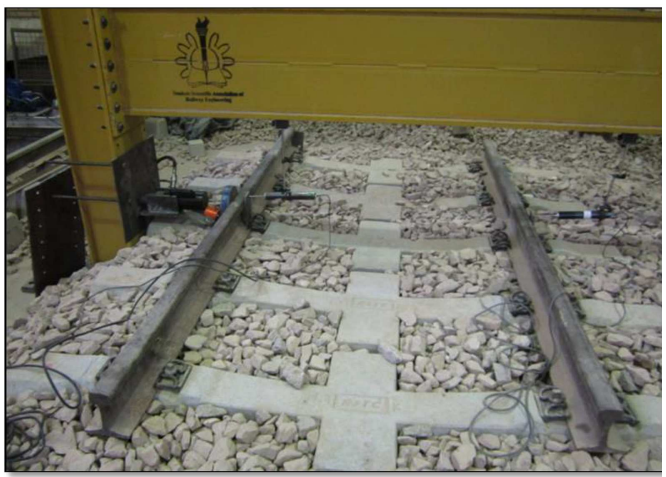

(b)

Figure 3. (a) Track panel loading test components (graphical modelling). (b) Track panel loading test of mid-winged concrete sleeper (physical modelling).

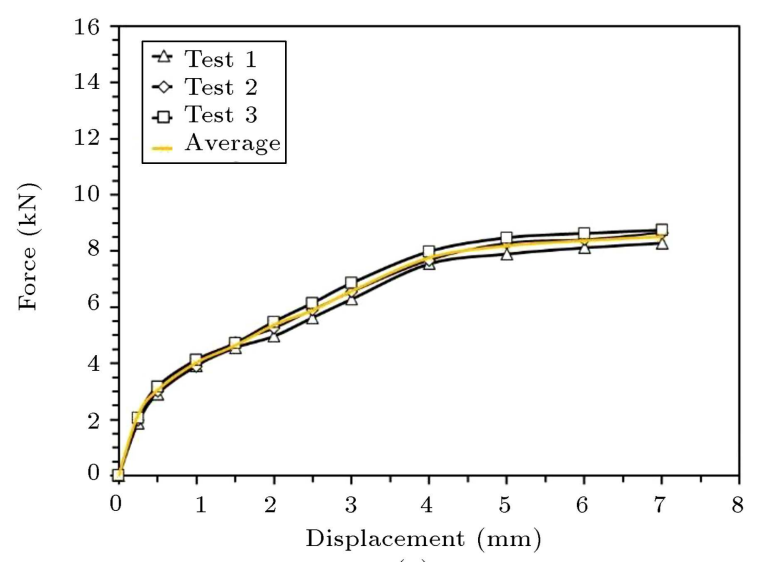

(a)

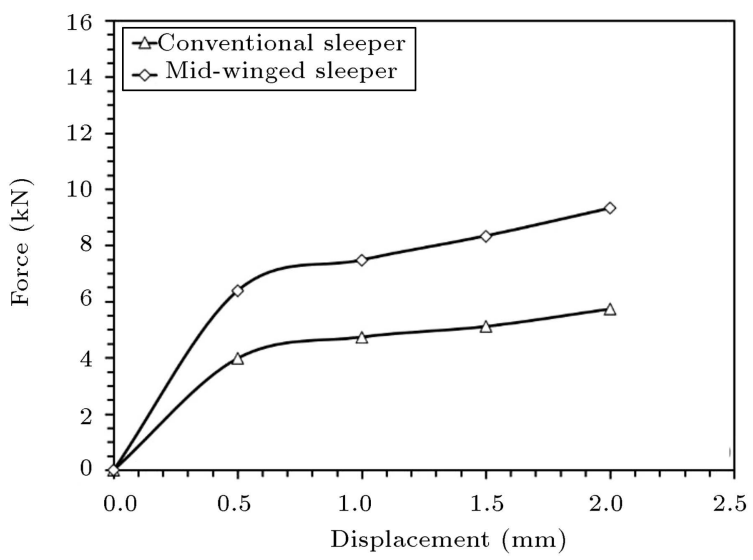

(c)

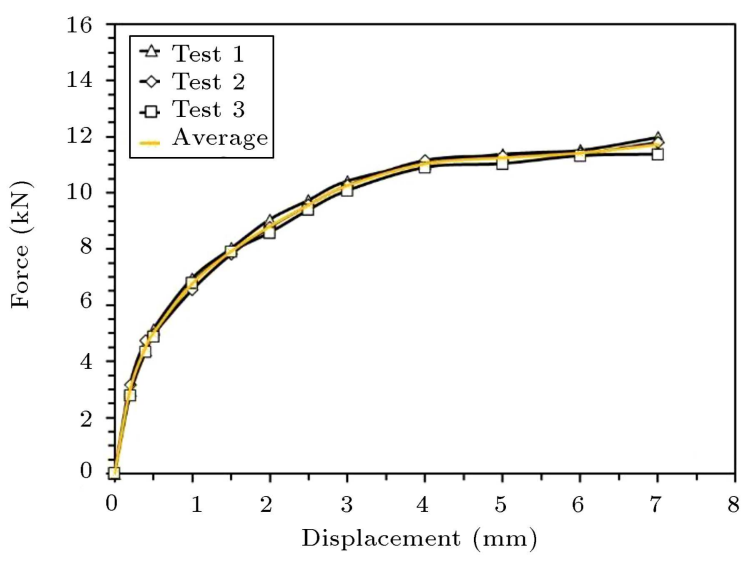

(b)

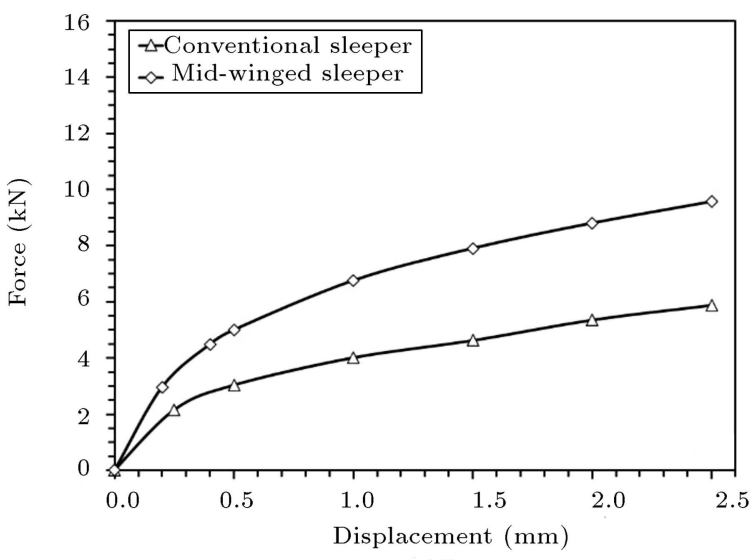

(d)

Figure 4. Lateral Track Panel Loading Test (LTPT) test results: (a) Conventional concrete sleeper, (b) mid-winged concrete sleeper, (c) comparison of Push Test (STPT) laboratory results from mid-winged and conventional sleeper, and (d) comparison of LTPT laboratory results from mid-winged and conventional sleeper.

standard value $[1,6]$ for the sleeper lateral displacement is $2 \mathrm{~mm}$, the test results are summarized in Figure 4(c).

The forces applied to both mid-winged and conventional sleepers to make the standard $2 \mathrm{~mm}$ displacement are $9.33 \mathrm{kN}$ and $5.74 \mathrm{kN}$, respectively. Accordingly, the required force to perform this displacement in mid-winged sleepers is 1.62 times that required in the conventional sleeper. As a result, the middle wing of the sleeper causes a $62 \%$ increase in the lateral resistance in the STPT test.

\subsection{Analysis of LTPT test results}

In this section, the LTPT test results for both midwinged and conventional sleepers are analyzed, and 
the obtained results are presented for each of these sleepers. Here, the standard value for the sleeper lateral movement is $2 \mathrm{~mm}$ and the test results are summarized in Figure 4(d).

The force rates exported into the mid-winged sleeper and conventional sleeper panel to make the displacement of the standard $2 \mathrm{~mm}$ are equal to $26.3 \mathrm{kN}$ and $16.1 \mathrm{kN}$, respectively. Accordingly, the required force to perform this displacement in the midwinged sleeper panel is 1.64 times that required for the conventional sleeper panel. Consequently, the middle wing of the sleeper causes $64 \%$ increase in lateral resistance in the LTPT test.

Given the above-mentioned values, $64 \%$ increase in the lateral sleeper resistance is achieved, which is significant. The effect of the changes in sleeper geometry reflects a substantial increase in the lateral resistance.

\section{Modeling of the tests carried out using FEM software}

This section discusses the numerical modeling of the lateral displacement of mid-winged and conventional sleepers using the ABAQUS finite element software. The results of the numerical modeling experiments were employed to validate the tests carried out at the laboratory and evaluate the behavior of the track panel. Of note, this modeling is performed based on MohrCoulomb model. In this model, the ballast elastoplastic behavior is simulated by importing the ballast characteristics. After trial and error, the optimal mesh size is assumed to be between 1 and $10 \mathrm{~cm}$. The panel connections are the connections between the rail and sleeper, sleeper and ballast, and ballast and bed. The following remarks can be made about these connections:

1. Since the type of binders has no effect on the lateral resistance, the connection between the binders is defined as tie;

2. The friction coefficients between the sleeper and ballast on the bed and sides (crib and shoulder ballast) are considered 0.8 and 0.3 , respectively;

3. According to the test conditions, the connection between the ballast and bed is also defined as tie.

\subsection{Modeling of the components}

To validate the model, an elastic mid-winged concrete sleeper and a ballast layer with a thickness of $30 \mathrm{~cm}$ and shoulder extent of $30 \mathrm{~cm}$ were employed. Given that the FEM software has a continuous space, the available ballast is modeled as a mass. Ballast mass is, in fact, a discrete space, the aggregates of which are isolated/un-bonded from each other. In this modeling, the ballast space is assumed to be an integrated mass (Figure 5(a)).

The most important specifications of the modeled sleeper and ballast are listed in Tables 2 and 3 .
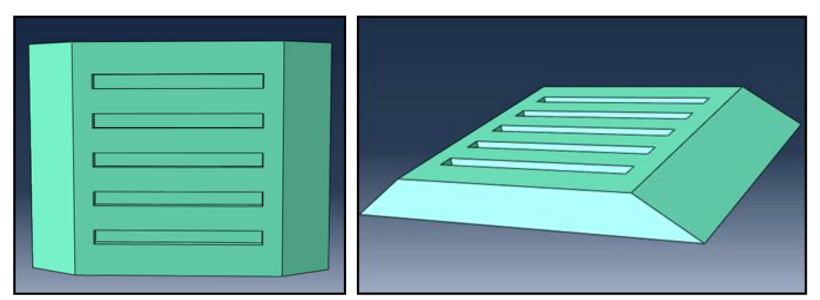

(a)
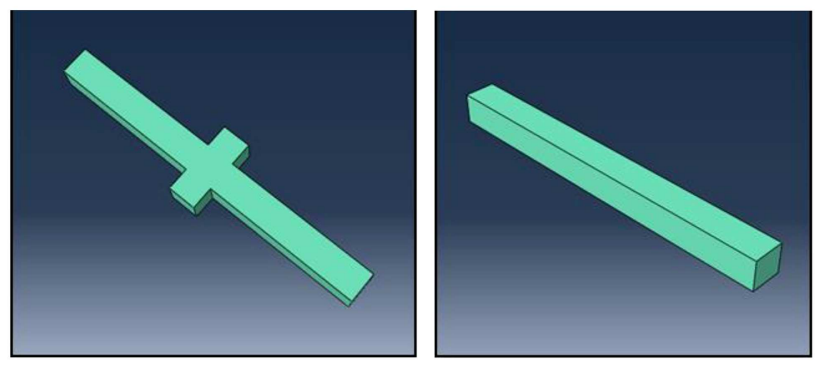

(b)

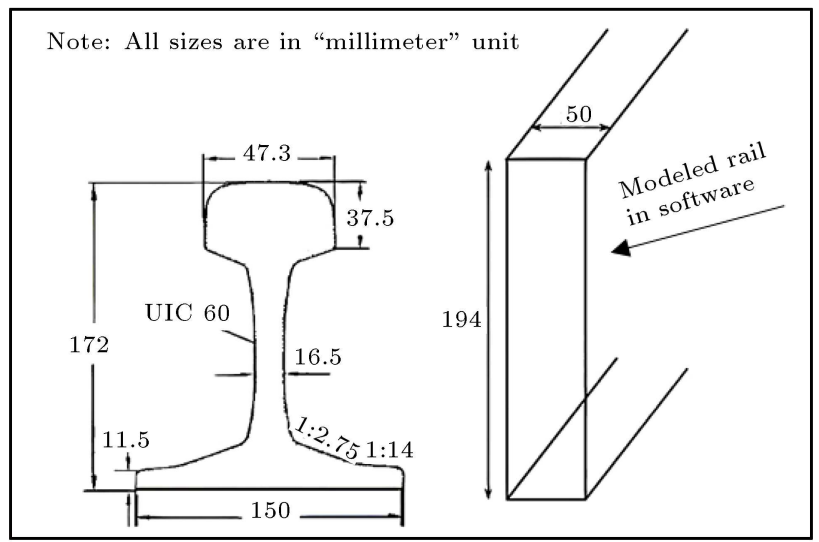

(c)

Figure 5. Modeled materials in software: (a) Ballast, (b) sleeper and (c) rail.

Table 2. Mechanical specifications of sleeper in FEM modeling.

\begin{tabular}{lcc}
\hline \multicolumn{1}{c}{ Feature } & Unit & Ballast \\
\hline Density & $\mathrm{kg} / \mathrm{m}^{3}$ & 2400 \\
Poisson's ratio & - & 0.15 \\
Young's modulus & $\mathrm{GPa}$ & 37.5 \\
\hline
\end{tabular}

Table 3. Mechanical specifications ballast in FEM modeling.

\begin{tabular}{lcc}
\hline \multicolumn{1}{c}{ Feature } & Unit & Ballast \\
\hline Density & $\mathrm{kg} / \mathrm{m}^{3}$ & 1500 \\
Poisson's ratio & - & 0.4 \\
Young's modulus & $\mathrm{GPa}$ & 0.05 \\
\hline
\end{tabular}


The next layer of the superstructure, the modeling of which should be considered, is the sleeper. With the lateral resistance calculated, the conventional concrete sleeper, as shown in Figure 5(b), is simulated as a cubic shape to simplify the analysis and to short the analysis steps. Table 2 presents the dimensions of the components of the modeled sleeper based on the studies already carried out and those available at the laboratory.

It is notable that in the molding of the panel, the track components such as sleeper type, fastening/joint system, and friction between rail and ballast were considered. The mentioned items are defined as follows:

Conventional sleeper: The typical sleeper dimensions are considered a rectangular cube with $220 \times 230 \times$ $2600(\mathrm{~mm})$.

Mid-winged sleeper: The values of the mid-winged sleeper are the same as those of the conventional one, except that a wing with dimensions of $580 \times 230(\mathrm{~mm})$ is attached to the center of the sleeper.

In this modeling, a simple equivalent model for rail was used, as illustrated in Figure 5(c) [27]. Upon displaying the components' specifications in the assembly software menu, the components are set one beside the other, as demonstrated in Figure 6(a).

Fastenings/joints in the panel: Fastening/joint of the rail to the sleeper, joint of the sleeper to the ballast, and joint of the ballast to the bed. A brief description of these joints is presented as follows:

- Since the type of fastenings does not influence the lateral resistance, the joint between the fastenings is defined as a tie type;

- The friction coefficients between the sleeper and ballast are 0.8 and 0.3 on the bed and sides, respectively;

- The joint of the ballast to the bed is defined as tie, based on the test conditions.

Friction between the sleeper and ballast: The ballast and sleeper are jointed in three areas [28]. The first area is the joint of the bottom of the sleeper to the ballast under the sleeper. The second area is the crib ballast and sleeper lateral surfaces. Finally, the third area is the joint between the end of the sleeper and shoulder ballast. Of these three zones, two zones/areas have friction: the friction between the concrete floor of the sleeper and particles of ballast and that between the crib ballast and the lateral surfaces of the sleeper (Figure 6(b)).

The forces involved in the track panel are the weights of the panel components including the static load which is horizontally imposed on the center of the panel on the rails. The panel weight is the total weight of the rails, sleepers, and fastenings [7].

The force horizontally imposed on the panel is the leading cause of movement on track and it is applied to rails at the center of the panel by a jack. The force

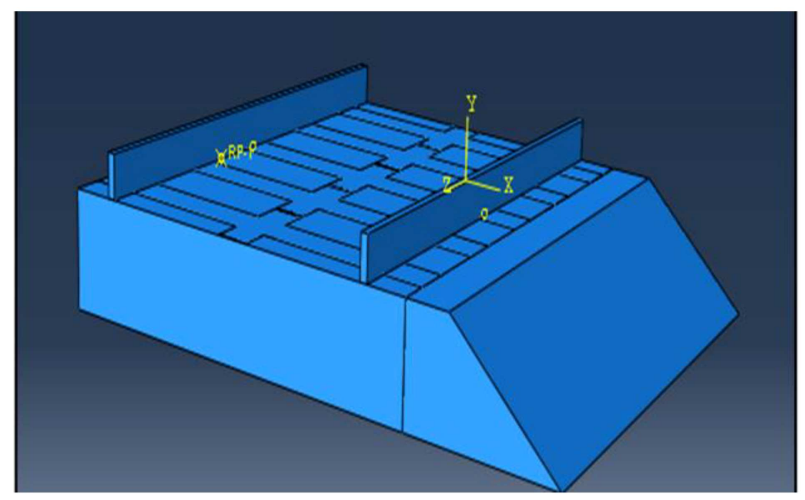

(a)
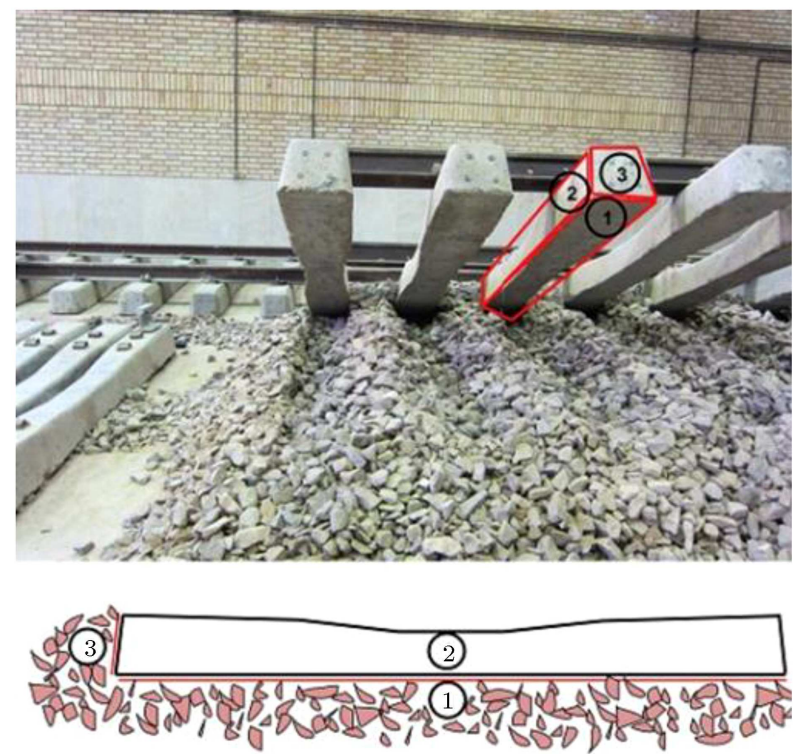

(b)

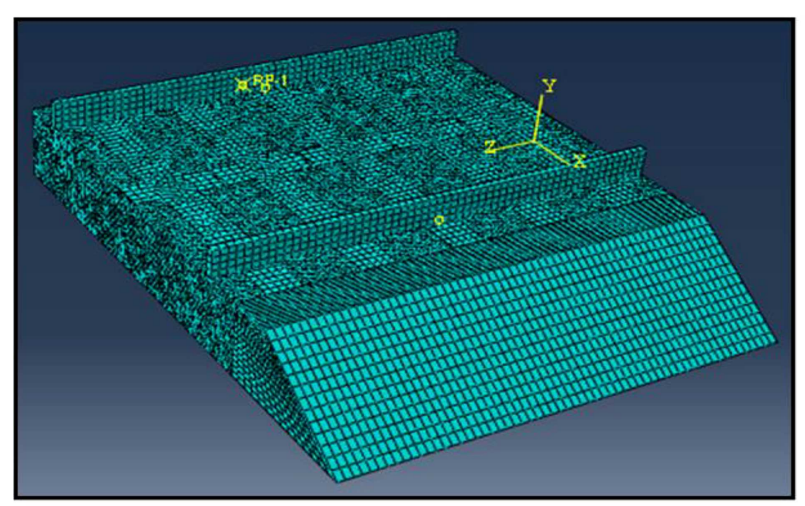

(c)

Figure 6. (a) Arrangement of components beside each other. (b) Contacted areas between ballast and sleeper. (c) Meshed panel. 
is, in fact, the modeling of the horizontal component of the force exported from the wheel to the rails in curves, applied to the panel by a jack at the laboratory.

\subsubsection{Meshing and analysis}

Using the square (aspect ratio equal to unity) or rectangular mesh is recommended for good accuracy and time saving [29]. In this paper, in order to model the ballast layer and sleeper, a square element with sides of $0.03 \mathrm{~m}$ was used. In addition, for modeling the shoulder ballast, a squared element with an aspect ratio of 2 was used. Networking and analysis of the model are done through the application of the joints of the respective components. The number of elements is of significance in determining the range of calculations. Based on the studies and measures, the increased number of elements and their decreased size are optimal. The increased number of elements to a certain extent ensures an accurate analysis of the obtained responses. However, after this specific limit, the responses do not undergo considerable changes and the rate of errors decreases enormously. In this situation, the large number of elements should only prolong the time required for analysis. Thus, during the analysis, the conventional limit on the number of elements is taken into account. In this modeling, improved meshing is achieved. In the meantime, the effect of mesh size on numerical displacement results with a constant force is provided in Table 4 .

\subsection{Panel modeling results}

This section discusses the modeling results. Of note, given the bonded modeling space in the FEM software and porosity of the actual ballast space, different values of the existing parameters are measured through trial and error, and the most influential parameter is the ballast Young's modulus. Although despite its variation, the outputs of the software are modeled with regard to the real-world conditions. Of note, Young's modulus, in such cases, is about $140 \mathrm{MPa}$.

As illustrated in Figure 7(a) and (b), displacement values can be observed based on different colors. Since the force is applied to the center of the track panel, the track panel displacement becomes more visible. Given that the force moves toward the sides of the track panel

Table 4. Effect of mesh size on the numerical displacement results with constant force.

\begin{tabular}{ccc}
\hline $\begin{array}{c}\text { Mesh size } \\
(\mathbf{c m})\end{array}$ & $\begin{array}{c}\text { Displacement } \\
(\mathbf{m m})\end{array}$ & $\begin{array}{c}\text { Error } \\
\mathbf{( \% )}\end{array}$ \\
\hline 10 & 0.4521 & 15.4 \\
8 & 0.4639 & 13.1 \\
6 & 0.4825 & 9.2 \\
5 & 0.5012 & 5 \\
3 & 0.5136 & 4 \\
2 & 0.5261 & 3.8 \\
1 & 0.5342 & - (reference) \\
\hline
\end{tabular}

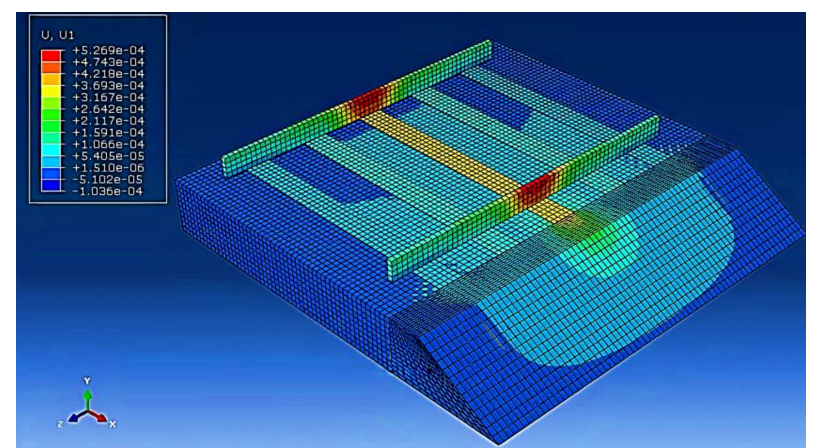

(a)

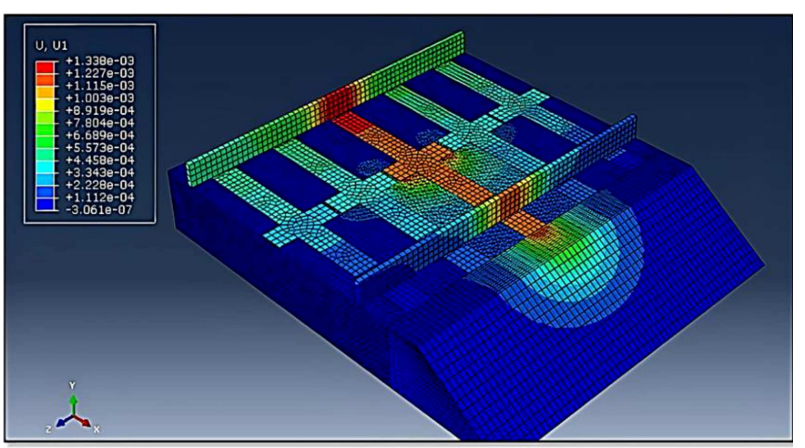

(b)

Figure 7. Displacement contours: (a) Conventional concrete sleeper and (b) mid-winged concrete sleeper.

while being kept away from the force center, the extent of displacement will be quite low.

\subsection{Comparison of results of panel modeling with conventional and mid-winged sleepers}

The results of modeling the track panel with midwinged and conventional sleepers are shown in Figure $8(\mathrm{a})$.

Given the values presented, the ratio of the lateral resistance of mid-winged sleeper to the conventional ones in the track panel lateral resistance modeling and displacement criteria of $2 \mathrm{~mm}$ is equal to 1.8 . Therefore, on average, $58 \%$ increase can be observed in the given modeling.

\section{Comparison and analysis of laboratory results and modeling}

Since the mid-winged sleeper has been tested for the first time, the laboratory results cannot solely confirm the outcomes. Hence, numerical modeling is carried out with the help of the software. Authors compared the results of the experiments performed at the laboratory with those of numerical modeling to validate the results presented in Figure 8(b) and (c).

Based on the already presented values, the difference between the lateral resistance of the conventional sleeper track panel at the laboratory and software modeling in the standard displacement of $2 \mathrm{~mm}$ is equal to $1.1 \mathrm{kN}$. As a result, the average inconsistency would 
be $6.8 \%$. For each given value, the difference between the lateral resistance of the mid-winged sleeper track panel at the laboratory and software modeling in the

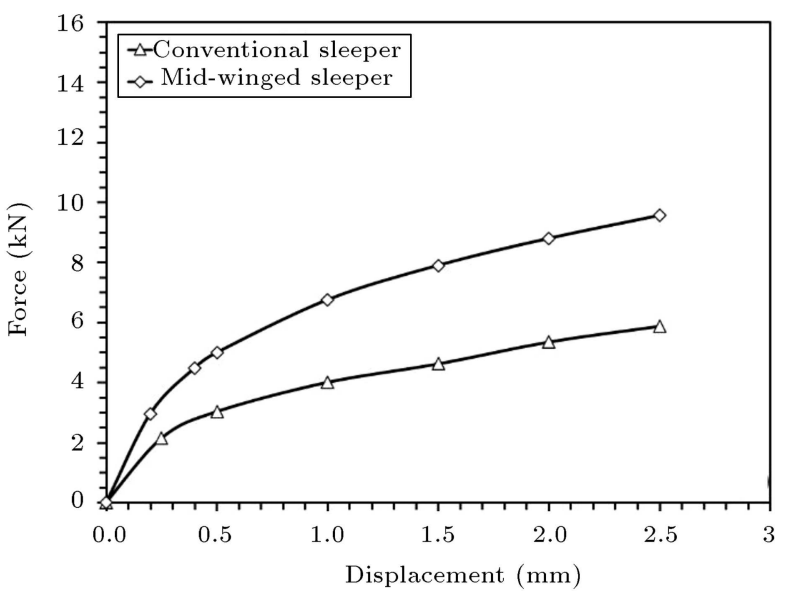

(a)

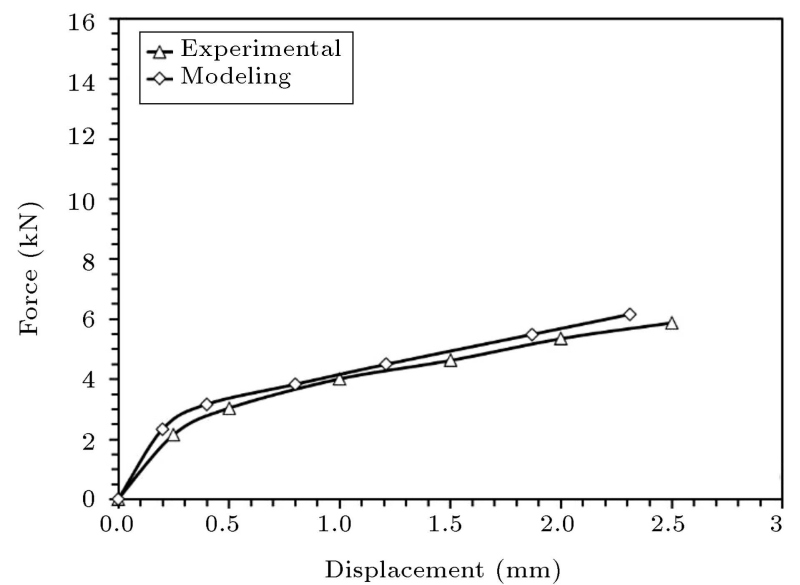

(b)

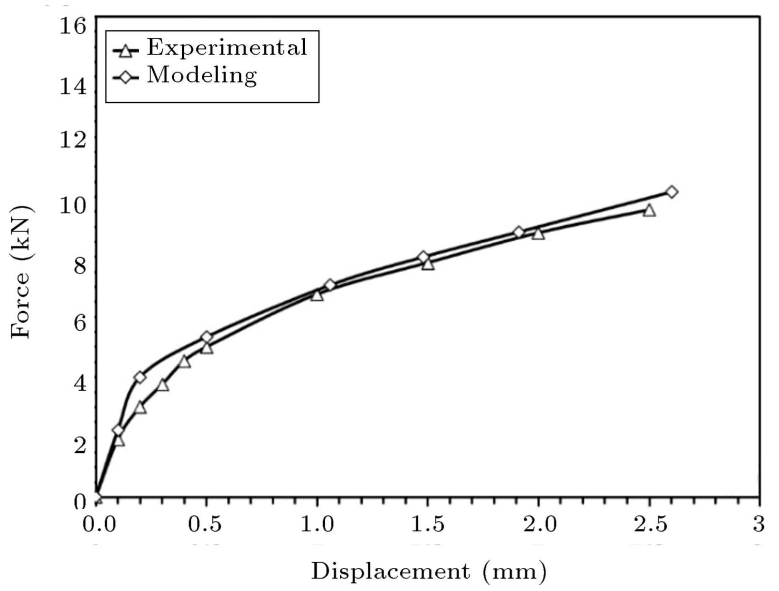

(c)

Figure 8. (a) Comparison of the results from modeling track panel and mid-winged and conventional sleepers. (b) Comparison of experimental and modeling results of the track panel and conventional concrete sleeper. (c) Comparison of experimental and modeling results of the track panel and mid-winged concrete sleeper. standard displacement of $2 \mathrm{~mm}$ is equal to $1.2 \mathrm{kN}$. Therefore, the average inconsistency is calculated as $3.05 \%$.

According to the results mentioned above, the laboratory values for the lateral resistance of midwinged sleepers are reliable/confidential and can be deemed as the criteria for further practicality.

\section{Conclusion}

This study carried out experiments on a single sleeper and examined the lateral resistance of the track panel with five sleepers. The results obtained from the single sleeper experiments indicated $62 \%$ increase in the track lateral resistance by replacing the conventional B70 concrete sleeper with the mid-winged sleeper.

The lateral resistance tests on the track panel in a continuous track also indicated $64 \%$ increase in the track lateral resistance by replacing the conventional concrete sleeper with the mid-winged sleeper in the track panel.

The numerical modeling on the track panel also illustrates that the modeling results were validated with the inconsistency of 3-7\%, hence being reliable.

According to results of this study, the track panel was tested with five sleepers; therefore, more sleepers in the track panel might be ineffective and $60 \%$ increase in the lateral resistance of the railway track would be acceptable.

Moreover, upon comparing the experimental results with those of the winged sleeper tests, it can be concluded that this type of sleeper might be a suitable alternative to replacing the winged sleeper. Of note, in terms of positioning the wing of the sleeper in the middle section, some problems arising during track maintenance operation, especially in track tamping process, could be resolved.

\section{References}

1. Zakeri, J.A., "Lateral Resistance of Railway Track", In Reliability and Safety in Railway, X. Perpinya, Ed., INTECH Open Access Publisher, pp. 357-374 (2012).

2. Zakeri, J.A., Mohammadzadeh, S., and Barati, M. "New definition of neutral temperature in continuous welded railway track curves", Period. Polytech. Civ. Eng., 62(1), pp. 143-147 (2018).

3. Jing, G. and Aela, P. "Review of the lateral resistance of ballasted tracks", Proceedings of the Institution of Mechanical Engineers, Part F: J. Rail Rapid Transit, 234(8), 8, pp. 807-820 (2020).

4. Zakeri, J.A. and Bakhtiary, A. "Comparing lateral resistance to different types of sleeper in ballasted railway tracks", Scientia Iranica, 21(1), pp. 101-107 (2014). 
5. Le Pen, L.M. and Powrie, W. "Contribution of base, crib, and shoulder ballast to the lateral sliding resistance of railway track: A geotechnical perspective", Proc. Inst. Mech. Eng. Part F J. Rail Rapid Transit, 225(2), pp. 113-128 (2011).

6. Zakeri, J.A. and Hassanrezaei, H. "Experimental investigation on effect of winged sleeper on lateral resistance of ballasted track", Scientia Iranica, 28(2), pp. 656665 (2021).

7. Zakeri, J.A., Mirfattahi, B., and Fakhari, M. "Lateral resistance of railway track with frictional sleepers", Proc. ICE - Transp., 165(2), pp. 151-155 (2012).

8. Zakeri, J.A. and Talebi, R. "Experimental investigation into the effect of steel sleeper vertical stiffeners on railway track lateral resistance", Proc. Inst. Mech. Eng. Part F: J. Rail Rapid Transit, 231(1), pp. 104110 (2017).

9. Sabaghi, S. "Investigation of track lateral resistance with anchored concrete sleepers", BSc Thesis, Iran University of Science and Technology (2013).

10. Pucillo, G.P., De Iorio, A., Rossi, S., et al. "On the effects of the USP on the lateral resistance of ballasted railway tracks", ASME/IEEE Joint Rail Conference (2018).

11. Jing, G., Qie, L., Markine, V., and Jia, W. "Polyure -thane reinforced ballasted track: Review, innovation and challenge", Constr. Build. Mater., 208, pp. 734748 (2019).

12. Darkhosh, M. "Field investigation on the effect of baby gabions on lateral resistance of ballasted railway tracks", MSc Thesis, Iran University of Science and Technology (2014).

13. Indraratna, B., Nimbalkar, S., Christie, D., Rujikiatkamjorn, C., et al. "Field assessment of the performance of a ballasted rail track with and without geosynthetics", J. Geotech. Geoenvironmental Eng., 136(7), pp. 907-917 (2010).

14. Kabo, E. "A numerical study of the lateral ballast resistance in railway tracks", Proceedings of the Institution of Mechanical Engineers, Part F: Journal of Rail and Rapid Transit, 220(4), pp. 425-433 (2014).

15. Zakeri, J.A., Esmaeili, M., Kasraei, A., and Bakhtiary, A. "A numerical investigation on the lateral resistance of frictional sleepers in ballasted railway tracks", Proceedings of the Institution of Mechanical Engineers, Part F: Journal of Rail and Rapid Transit, 230(2), pp. 440-449 (2014).

16. Kerr, A.D. "Railroad track mechanics and technology", Proceedings of a Symposium Held at Princeton University, pp. 21-23, April (1975). Elsevier (2014).

17. Montalbán Domingo, L., Real Herraiz, J.I., Zamorano, C., et al. "Design of a new high lateral resistance sleeper and performance comparison with conventional sleepers in a curved railway track by means of finite element models", Latin American Journal of Solids and Structures, 11(7), pp. 1238-1250 (2014).

18. Koike, Y., Nakamura, T., Hayano, K., et al. "Numerical method for evaluating the lateral resistancr of sleeper in ballasted tracks", Soils Found., 54(3), pp. 502-514 (2014).

19. Hayano, K., Koike, Y., Nakamura, T., et al. "Effects of sleeper shape on lateral resistance of railway ballasted tracks", In Advances in Soil Dynamics and Foundation Engineering, pp. 491-499 (2014).

20. Jing, G.Q., Aela, P., Fu, H., et al. "Numerical and experimental analysis of single tie push tests on different shapes of concrete sleepers in ballasted tracks", Proceedings of the Institution of Mechanical Engineers, Part F: J. Rail Rapid Transit, 233(7), 666-677 (2019).

21. Jing, G., Ji, Y., and Aela, P. "Experimental and numerical analysis of anchor-reinforced sleepers lateral resistance on ballasted track", Construction and Building Materials, 264, p. 120197 (2020).

22. Jing, G., Ding D., and Liu, X. "High-speed railway ballast flight mechanism analysis and risk management-A literature review", Construction and Building Materials, 223, pp. 629-642 (2019).

23. Jing, G.Q., Aela, P., Fu, H., et al. "Numerical and experimental analysis of lateral resistance of biblock sleeper on ballasted tracks", International Journal of Geomechanics, 20(6), 04020051 (2020).

24. Khatibi, F., Esmaeili, M., and Mohammadzadeh. S. "DEM analysis of railway track lateral resistance", Soils and Foundations, 57(4), pp. 587-602 (2017).

25. Technical-General Specifications for Railway Track Superstructure, published by Iran Planning and Strategic Bureau of Presidential Office, Islamic Republic of Iran, Leaftec No. 301 (2005).

26. ASTM C136/CI36M-19, Standard Test Method for Sieve Analysis of Fine and Coarse Aggregates (2014).

27. Esmaeili, M., khodaverdian, A., Kalantar Neyestani, H., et al. "Investigating the effect of nailed sleepers on increasing the lateral resistance of ballasted track", Computers and Geotechnics, 71, pp. 1-11 (2016).

28. Bakhtiari, A., Zakeri, J.A., Fang, H.J., et al. "An experimental and numerical study on the effect of different types of sleepers on track lateral resistance", Int., J. of Trans. Eng., 3, pp. 7-15 (2015).

29. Shuber, A., Hamood, M., and Jawad, W. "Performance of railway track system under harmonic loading by finite element method", In MATEC Web of Conferences, 162, p. 01043. EDP Science (2018).

\section{Biographies}

Behnam Sadollahzadeh is now a $\mathrm{PhD}$ student in Geotechnical Engineering at the Department of Civil Engineering, Sharif University of Technology (SUT), Tehran, Iran. His research interests include railway 
superstructure, railway substructure, and unsaturated soils (especially experimental research). He received his BSc degree in Railway Track and Structures Engineering from Iran University of Science and Technology in 2015. In 2017, he graduated from SUT with an MSc degree in Geotechnical Engineering, Department of Civil Engineering.

Jabbar-Ali Zakeri received his $\mathrm{PhD}$ degree in Road and Railway Engineering from Beijing Jiaotong University, China, in 2000. Dr. Zakeri is currently a Professor at the School of Railway Engineering, Iran University of Science and Technology. His research interests include dynamic analysis of train-track interaction, railway track dynamics, track maintenance, and construction.
Hemed Nouri Gheshlaghi received his BSc and MSc degrees in Railway Track and Structures Engineering from Iran University of Science and Technology in 2015 and 2018, respectively. His research interests include analysis of railway track resistance.

Amin Hasani Motlagh received his BSc degree from Amirkabir University of Technology (AUT) in 2018 Tehran, Iran. He continued his study program as a MSc student in Geotechnical Engineering at Sharif University of Technology (SUT), Tehran, Iran. He is now working on the reliable characterization and theorization of complex multi-phase flow through highly deformable unsaturated porous media. His research interests are porous media, environmental geotechnics, and numerical analysis. 